\section{Growth Response of One-year-old 'Granny Smith' Apple Branches in Relation to Time of Heading}

\author{
S.A. Oosthuyse', G. Jacobs, and D.K. Strydom² \\ Department of Horticultural Science, University of Stellenbosch, \\ Stellenbosch, Republic of South Africa \\ Additional index words. Malus domestica, pruning, blindwood, apical dominance, \\ budbreak, shoot growth
}

Abstract. $\quad$ Upright l-year-old apple (Malus domestica Borkh. 'Granny Smith') branches were headed at 14-day intervals (branches headed once each) during late winter and in spring [70 days before full-bloom (DBFB) until 28 days after full-bloom (DAFB)] and budbreak and new shoot growth quantified on the remaining branch section after cessation of these events. When heading was performed 70, 56, or $42 \mathrm{DBFB}$, four to five buds broke on average. When branches were headed subsequently, the average number of buds breaking increased progressively, then decreased with heading date, the maximum number breaking (13) on branches headed 14 DAFB. An average of 10 or 11 buds broke per branch section when heading was performed 28 DAFB. In late summer, the total length of new shoots per branch section for the branches headed before full bloom averaged $113 \mathrm{~cm}$, whereas that on the branches headed at or after full-bloom averaged $76 \mathrm{~cm}$.

Branches of 'Granny Smith' apple trees are conspicuously unbranched over a large portion of their length because of the failure of proximally situated buds to break on 1year-old branches in spring. The unbroken buds continue to remain dormant on the tree, thus giving rise to a condition known as "blind wood." New shoots arising from the distal end of 1-year-old branches grow vigorously and vertically. The growth habit, characterized by bare branches terminating in vigorous upright growth, is undesirable for the following reasons: much of the interior canopy of the bearing tree is devoid of spurs and is thus unproductive. Fruit borne distally on 1-year-old branches cause top heaviness and limb bending later in the growing season, with the consequent result of fruit and bark being exposed to solar injury. Solar injury to the bare branches of young trees commonly occurs as a result of inadequate shading by the tree canopy. In newly planted trees, training is often difficult due to an inadequacy of lateral branching.

It is generally recognized by apple growers in South Africa that budbreak on 1-yearold 'Granny Smith' apple branches can be

Received for publication 3 June 1991. Accepted for publication 23 Jan. 1992. The cost of publishing this paper was defrayed in part by the payment of page charges. Under postal regulations, this paper therefore must be hereby marked advertisement solely to indicate this fact.

'Present address: Merensky Technological Services, P.0. Box 14, Duivelskloof, Republic of South Africa.

Present address: Ceres Fruit Growers, Private Bag X67, Ceres, Republic of South Africa. increased by delaying heading until spring, though the relationship between the time of heading and the number of buds breaking has not been quantified.

The purpose of this study was to quantify the effect of heading intact 1-year-old 'Granny Smith' branches on successive dates during late winter and in spring on budbreak and days after full bloom (24 Nov.). new shoot growth on the remaining branch section.

In early Aug. 1983, 78 days before full bloom (DBFB), 10 vertically oriented 1-yearold branches between 110 and $119 \mathrm{~cm}$ long were selected in each of eight adjacent, 6year-old 'Granny Smith' apple trees at the university experimental farm, Welgevallen. A randomized-block design was used where single branches served as plots, and the branches selected within a tree comprised a complete block.

Ten of the branches were headed at one time, a set every 14 days from 18 Aug. (70 DBFB) until 24 Nov. (28 DAFB). Two-thirds of the original length of each branch was left. After the period of heading, when buds were no longer breaking, the number of broken and dormant buds per branch section was counted. In late summer, when shoots had ceased extending, the total length of new shoots per branch section was measured.

The data were respectively subjected to analysis of variance where the sum of squares for treatments was orthogonally and completely partitioned for reductions due to successive polynomial terms. The means and polynomial of degree of the highest term for which the reduction in variability was significant $(P<0.05)$ were plotted. Due to marked variance heterogeneity relating to treatment, the number of buds broken and total length of new shoots per branch section were transformed to their natural logarithms and square roots, respectively, and the analyses performed on the transformed data. In

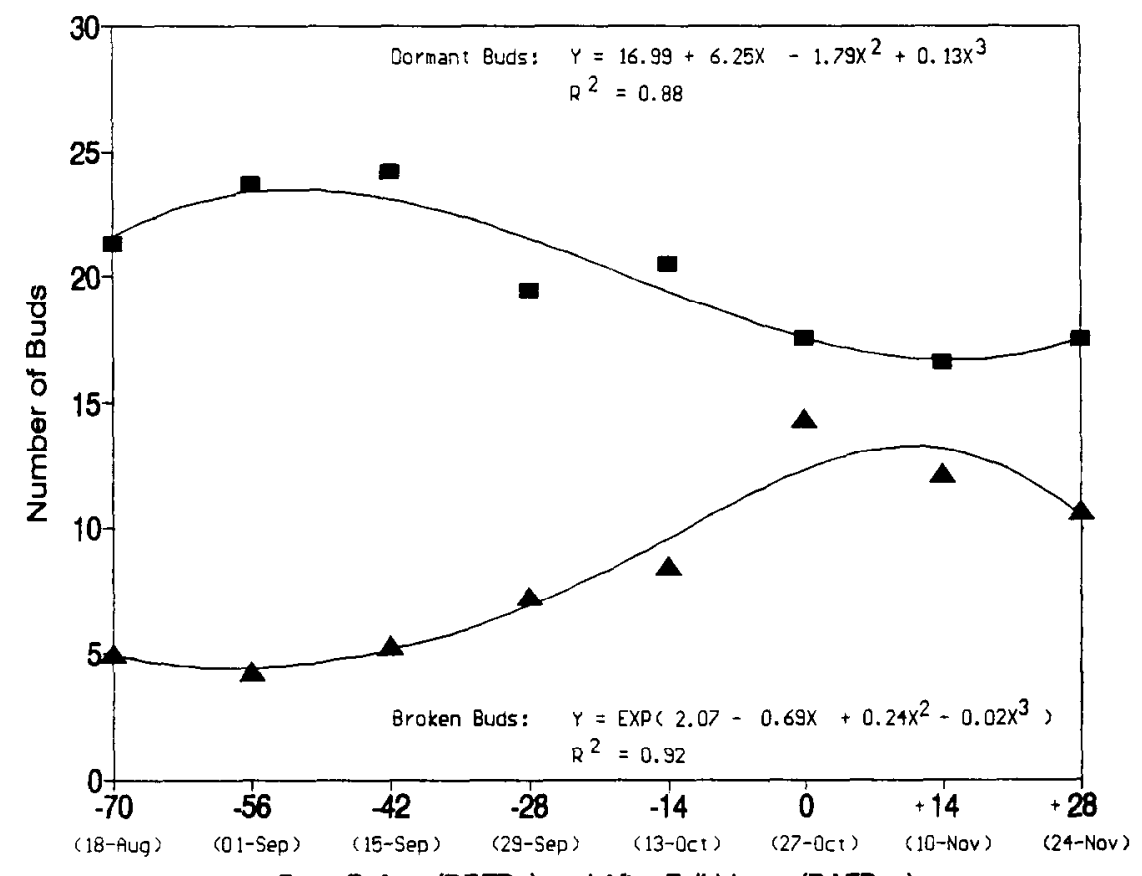

Days Before (DBFB -) and After Full-bloom (DAFB +)

Fig. 1. Number of buds breaking or remaining dormant on the remaining section of 1-year-old 'Granny Smith' apple branches headed at 14-day intervals from 70 days before full bloom (18 Aug.) until 28 


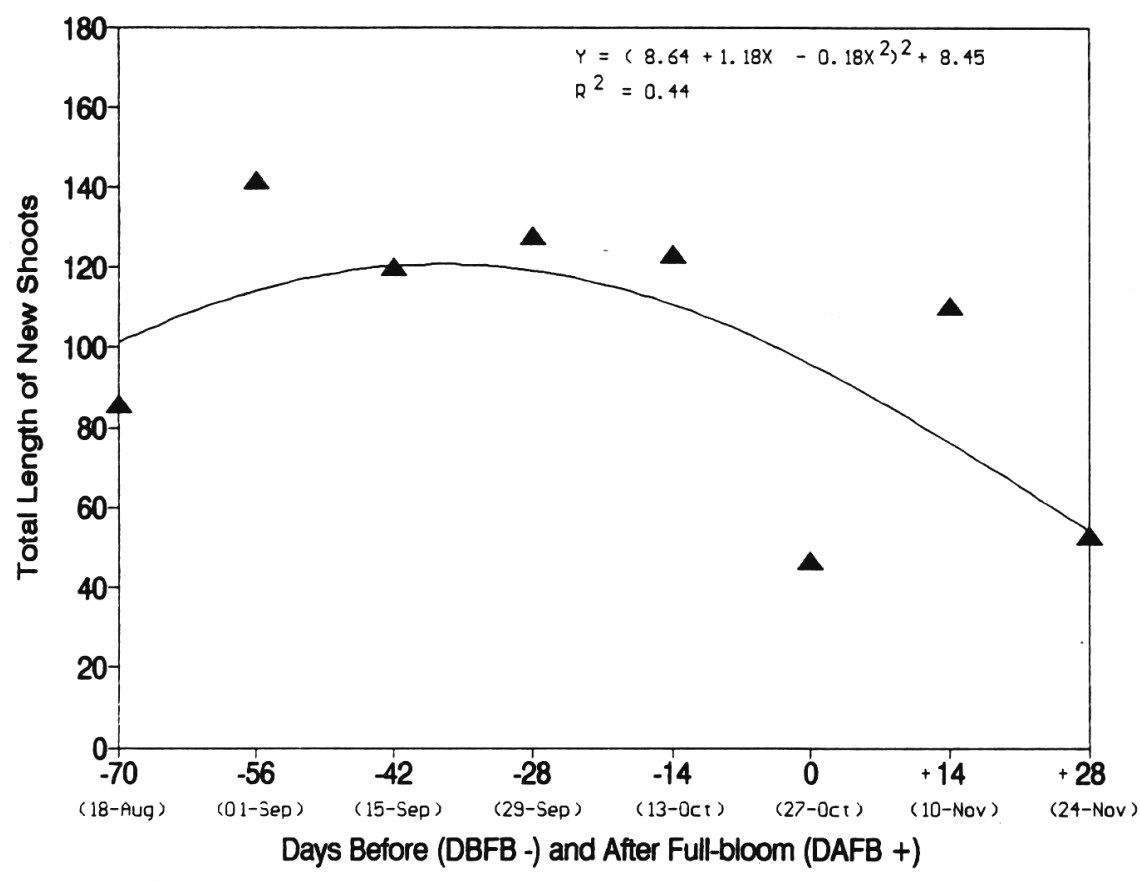

Fig. 2. Total length of new shoots on the remaining section of 1-year-old 'Granny Smith' apple branches headed at 14-day intervals from 70 days before full bloom (18 Aug.) until 28 days after full bloom (24 Nov.).

each case, the detransformed means and detransformed polynomial were plotted, employing the adjustments suggested by Quenouille (1953). Curve-plotting was meant to facilitate the interpretation of the variation of the means. The data were interpreted in terms of the "averages" predicted by the estimating equations.

Fruit on the remaining branch sections were allowed to develop to maturity. The trees used were managed according to normal commercial practice. General pruning was performed at the time of spring budbreak.

The number of buds breaking varied according to heading date (Fig. 1). When heading was performed 70,56 , or 42 DBFB, four or five buds broke on average per remaining branch section. When branches were headed subsequently, the average number of buds breaking progressively increased, then decreased with heading date, the maximum number breaking on branches headed 14 DAFB. Here, an average of 13 buds broke per branch section. Heading 28 DAFB on 24 Nov., when new shoots were beginning to elongate, resulted in an average of 10 or 11 buds breaking per branch section. Irrespective of heading date, the number of buds that remained dormant exceeded the number of buds that broke and grew.

The total length of new shoots per remaining branch section increased then decreased with heading date (Pig. 2). When heading was performed before full bloom, total length averaged $113 \mathrm{~cm}$, whereas when heading was performed at or after full bloom, total length averaged $76 \mathrm{~cm}$.

Budbreak was confined to the uppermost nodes, particularly on the branches headed before full bloom. Total length of new shoots was highest for the branch sections on which relatively few buds broke. Consequently, the branches headed before full bloom were largely unbranched in late summer, branching having occurred near the heading cut where a few new shoots had grown vigorously. Fruit borne on these branch sections caused them to become top heavy and bend over in summer. As a result, both the fruit and exposed bark were subjected to solar injury.

Niew shoots and fruit were more evenly distributed along the length of the branches headed at or after full bloom. These branches remained erect throughout the growing season. Figure 3 illustrates the general appearance of the branches headed before full bloom and of the branches headed at or after full bloom.

Bud development immediately beneath the cut of the branches headed before spring budbreak was advanced. During the third week of October when budbreak was general, the resulting new shoots appeared as clusters of primary leaves, the size of a leaf cluster portraying its age. Stimulated budbreak in response to heading was observed elsewhere (Paiva and Robitaille, 1978; Williams et al., 1979) and is probably a wounding response.

Apicies and expanding leaves are known to inhibit the development of axillary buds in many deciduous trees (Jankiewicz and Stecki, 1976). The potential of a new shoot to elongate has been positively linked to the degree of its development early in the growing season (Cannon, 1941; Jankiewicz, 1972; Jankiewicz et al., 1967; Maggs, 1958, 1959). Jankiewicz (1972) proposed a cybernetic model to explain patterns of new shoot growth on 1-year-old apple branches. According to the model, new shoots that are slightly ahead

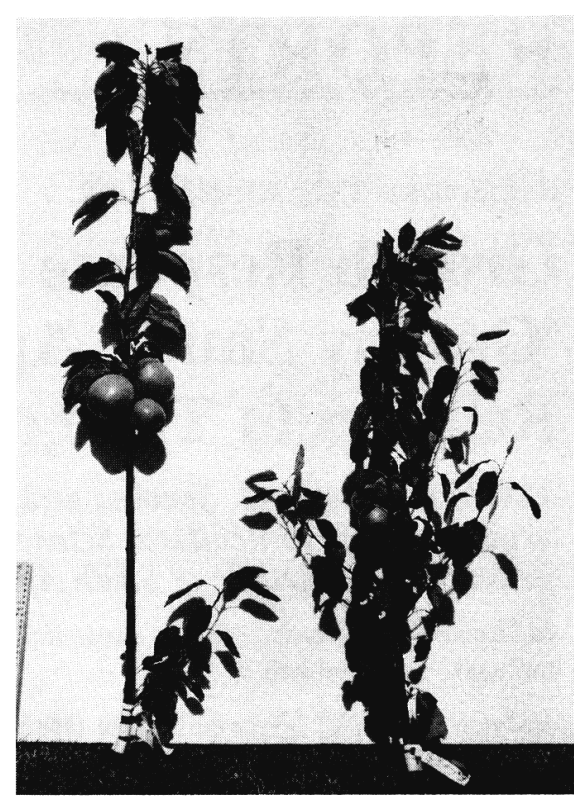

Fig. 3. Remaining section of a 1-year-old 'Granny Smith' apple branch headed before full bloom in early September (left), and of a branch headed after full bloom in mid-November (right). Note the difference in location of fruit and distribution of new shoots along the branch length. in their development in spring are slightly better producers of auxin, making them quick to become established sinks for metabolites, and to monopolize available substances required for growth.

A direct relationship between the size of a leaf cluster at the onset of spring budbreak, and its potential to elongate as well as inhibit budbreak, would largely explain the increase in number of buds breaking with heading date and the increased total length of new shoots on the branches headed before full bloom.

The reduction in budbreak when heading was performed 28 DAFB, on 24 Nov., might be ascribed to, for instance, the depletion of reserve materials in the branch before heading by distally located new shoots (Gregory and Veale, 1957; Hansen, 1971; Harley et al., 1958; Mika, 1986), or the reduced supply of root-produced cytokinins following a reduction in root activity later in spring (Grochowska et al., 1984; Luckwill, 1970; Skene, 1975; Tukey, 1981; Wareing et al., 1977).

Irrespective of when heading was performed, an appreciable number of buds remained dormant. Champagnat (1961) claimed, when referring to branches with an acrotonic pattern of lateral branching, that buds at the apical end are predisposed to fast growth, whereas buds at the basal end are predisposed to dormancy. Maggs (1963) came to a similar conclusion, stating that apple buds are increasingly inhibited from sprouting toward the branch base. Such a gradient may be inherently more pronounced in 'Granny Smith' than in other apple cultivars and is possibly the primary cause for the conspicuous occurrence of blind wood in this cultivar. Our results clearly show, however, that the pattern of budbreak and new 
shoot growth from 1-year-old 'Granny Smith

apple branches can be favorably altered by delaying heading until at or soon after full bloom.

\section{Literature Cited}

Cannon, H.B. 1941. Studies in the variation of nursery fruit trees on vegetatively raised rootstocks. J. Pomol. 19:2-33.

Champagnat, P. 1961. Dominance apicale, tropismes, epinastie. Handbuch der Pflanzenphysiologie. Vol. 14:872-877.

Gregory, F.G. and J.A. Veale. 1957. A reassessment of the problem of apical dominance. Soc Expt. Biol. Symp. 11:2-20.

Grochowska, M.J., A. Karaszewska, B. Jankowska, J. Maksymiuk, and M.W. Williams. 1984. Dormant pruning influence on auxin, gibberellin, and cytokinin levels in apple trees. J. Amer. Soc. Hort. Sci. 109:312-318.

Hansen, P. 1971. ${ }^{14} \mathrm{C}$-Studies on apple trees. VII. The early seasonal growth in leaves, flowers and shoots as dependent upon current photosynthates and existing reserves. Physiol. Plant. 25:469-473.

Harley, C.P., L.O. Regeimbal, and H.H. Moon. 1958. The role of nitrogen reserves in new growth of apple and the transport of $\mathrm{P}^{32}$ from roots to leaves during early spring growth. Proc. Amer. Soc. Hort. Sci. 72:57-63.

Jankiewicz, L.S. 1972. A cybernetic model of growth correlation in young apple trees. Biol. Plant. 14:52-66.

Jankiewicz, L.S. and Z.J. Stecki. 1976. Tree physiology and yield improvement, p. 157-172. In: M.G.R. Cannel1 and F.T. Last (eds.). Some mechanisms responsible for difference; in tree form. Academic, London.

Jankiewicz. L.S.. W. Srezednicka. and B. Borkowska. 1967: Gravimorphism in the poplar (Populus sp.). Bul. Acad. Polon Sci. CI.V 15:111-113.

Luckwill, L.C. 1970. The control of growth and fruitfulness of apple trees. Proc. Symp. Long Ashton Res. Sta. p. 237-254.

Maggs, D.H. 1958. A comparison of the growth patterns of two apple rootstock varieties during their first year. E. Malling Res. Sta., Annu. Rpt. 1957, p. 101-105.

Maggs, D.H. 1959. The effect of the original situation of the scion on its subsequent growth. E Malling Res. Sta. Annu. Rpt. 1958. p. 83-85.

Maggs, D.H. 1963. Some pre-planting factors in the establishment of young trees. E. Malling Res. Sta. Annu. Rpt. 1962. p. 81-88.

Mika, 1986. Physiological responses of fruit trees to pruning. Hort. Rev. 8:337-378.

Paiva, E. and H.A. Robitaille. 1978. Breaking bud rest on detached apple shoots: Effects of wounding and ethylene. J. Amer. Soc. Hort. Sci. 103:101-104

Quenouille, J.D. 1953. The design and analysis of experiment. Charles Griffin. London.

Skene, K.G.M. 1975. Cytokinin production by roots as a factor in the control of plant growth p. 365-395. In: J.G. Torrey and D. Clarkson (eds.). The development and function of roots. Academic, New York.

Tukey, L.D. 1981. Growth and development in tree fruits, p. 1-62. In: R.B. Tukey and M.W. Willlams (eds.). Tree fruit growth regulators and chemical thinning. Shortcourse proceeding 1981. Coop. Ext., Washington State Univ. Pullman.

Wareing, P.F., R. Horgan, J.E. Henson, and P. Davis. 1977. Cytokinin relation in whole plants, p. 147-153. In: P.E. Pilet (ed.). Plant growth regulation. Springer-Verlag, Berlin.

Williams, R.R., G.R. Edwards, and B.G. Coombe. 1979. Determination of the pattern of winter dormancy in lateral buds of apples. Ann. Bot. 44:575-581. 